\title{
PENERAPAN METODE PEMBELAJARAN GUIDE NOTE TAKING (GNT) UNTUK MATERI SPLDV PADA KELAS VIII SMP
}

\author{
Maria Anita Sero ${ }^{1}$, Juwita Merdja ${ }^{2}$, Ariswan Usman Aje $^{3}$ \\ ${ }^{1}$ Program Studi Pendidikan Matematika Universitas Flores, Jalan Sam Ratulangi, Ende-Flores-NTT \\ ${ }^{2}$ Universitas Flores, Jln. Sam Ratulangi, Ende-Flores-NTT \\ ${ }^{3}$ Universitas Flores, Jln. Sam Ratulangi, Ende-Flores-NTT \\ Email: juwitamerdja@gmail.com
}

\begin{abstract}
This study aims to determine (1) Guide Note Taking (GNT) learning tools on a two-variable linear equation system in class VIII students of SMPK Swadaya Maukaro in the 2018/2019. (2) Learning outcomes through learning Guide Note strategies Taking (GNT) material on the two-variable linear equation system for class VIII SMPK Swadaya Maukaro in the 2018/2019. This type of research used in this research is experimental research with the approach used is a quantitative approach. The subjects in this study were 20 students of class VIII SMPK Swadaya Maukaro. The research result states that the results of the preparation of the Guide Note Taking learning tool for the two-variable linear equation system material produce a good learning tool because it meets the requirements based on validity, reliability, and sensitivity. Results of covariance data analysis obtained $f$-count $=5.241>f$ table $=4.45$ or it can be seen that the $P$ value $=0.347>$ $\alpha=0.05$ with dk numerator 1 and dk denominator 19, giving a significant value, then this shows that learning Guide Note Taking is considered to be able to improve learning outcomes for the material of two-variable linear equation systems in class VIII students of SMPK Swadaya Maukaro.
\end{abstract}

Keywords: guide note taking; study result; linear equation system.

\begin{abstract}
Abstrak
Tujuan yang ingin dicapai dalam penelitian ini adalah untuk mengetahui (1) Menghasilkan Perangkat pembelajaran Guide Note Taking (GNT) pada sistem persamaan linear dua variabel pada siswa kelas VIII SMPK Swadaya Maukaro Tahun Pelajaran 2018/2019.(2) Hasil belajar melalui pembelajaran strategi Guide Note Taking (GNT) materi sistem persamaan linear dua variabel kelas VIII SMPK Swadaya Maukaro tahun pelajaran 2018/2019. Jenis penelitian yang digunakan dalam penelitian ini adalah penelitian eksperimen dengan pendekatan yang digunakan adalah pendekatan kuantitatif. Subyek dalam penelitian ini adalah siswa kelas VIII SMPK Swadaya Maukaro yang berjumlah 20 orang. Hasil penelitian menyatakan bahwa hasil penyusunan perangkat pembelajaran Guide Note Taking untuk materi sistem persamaan linear dua variabel menghasilkan perangkat pembelajaran yang baik, karena memenuhi syarat berdasarkan validitas, reliabilitas dan sensitivitas. Dan hasil analisis data kovarian diperoleh $\mathrm{f}$-hitung $=5.241>\mathrm{f}$-tabel $=4.45$ atau dapat dilihat nilai $\mathrm{P}$-value $=0.347>\alpha=0.05$ dengan $\mathrm{dk}$ pembilang $1 \mathrm{dan} \mathrm{dk}$ penyebut 19 , memberikan nilai yang signifikan, maka hal ini menunjukkan bahwa pembelajaran Guide Note Taking dinilai dapat meningkatkan hasil belajar untuk materi sistem persamaan linear dua variabel pada siswa kelas VIII SMPK Swadaya Maukaro.
\end{abstract}

Kata kunci: GNT; hasil belajar; sistem persamaan linear.

\section{PENDAHULUAN}

Sekolah sebagai lembaga pendidikan yang menyelenggarakan proses belajar mengajar, serta mempunyai peranan penting dalam mentransfer pengetahuan dan keterampilan kepada siswa. Peranan tersebut diharapkan dapat menghasilkan manusia-manusia yang berkualitas dalam bidang pengetahuan keterampilan dan sikap (Pleimaget, 2019). Pendidikan merupakan suatu peristiwa 
Penerapan Metode Pembelajaran Guide Note Taking (GNT) Untuk Materi SPLDV

Pada Siswa Kelas VIII SMPK Swadaya Maukaro

Maria Anita Sero ${ }^{1, J u w i t a}$ Merdja $^{2}$, Ariswan Usman Aje ${ }^{3}$

Jupika: Jurnal Pendidikan Matematika, Volume 3. Nomor 2. September 2020. Hal.101-110

kompleks dimana terjadinya rangkaian kegiatan komunikasi antara manusia sehingga tumbuh dan berkembang sebagai pribadi yang utuh. Hal ini sejalan dengan Syaiful (2003) yang mengatakan pendidikan adalah usaha yang dilakukan oleh keluarga, masyarakat melalui kegiatan bimbingan pengajaran dan pelatihan yang berlangsung di sekolah maupun luar sekolah. Dalam dunia pendidikan sekolah menengah terdapat beberapa mata pelajaran yakni Matematika, IPA, IPS, Bahasa Inggris, Bahasa Indonesia dan masih banyak mata pelajaran yang lain.

Dalam pembelajaran di sekolah matematika merupakan ratunya ilmu dan sekaligus menjadi pelayannya yang memiliki arti bahwa matematika merupakan sumber dari segala disiplin ilmu dan kunci ilmu pengetahuan (Rachmayani, 2014). Matematika juga berfungsi untuk melayani ilmu pengetahuan artinya selain tumbuh dan berkembang untuk dirinya sendiri sebagai suatu ilmu, matematika juga melayani kebutuhan ilmu pengetahuan dalam pengembangan dan operasionalnya (Suherman, 2001). Definisi tersebut memberi arti bahwa matematika merupakan ilmu dasar, baik aspek terapannya maupun aspek penalarannya yang mempunyai peranan penting dalam upaya penguasaan ilmu pengetahuan dan teknologi. Melihat begitu pentingnya matematika di segala bidang ilmu pengetahuan, pembelajaran matematika dimasukkan ke dalam semua jenjang pendidikan di Indonesia mulai dari sekolah dasar hingga perguruan tinggi (Rachmayani, 2014). Oleh sebab itu siapa yang menguasai matematika maka mata pelajaran yang lain akan mudah dilakukan.

Menurut Lebi, (2020) matematika sebagai salah satu mata pelajaran di sekolah dinilai sangat memegang peranan penting, karena matematika dapat meningkatkan pengetahuan siswa dalam berpikir secara logis, rasional, kritis, cermat, efektif dan efesien. Oleh karena itu, pengetahuan matematika harus dikuasai sedini mungkin oleh siswa. Dalam proses pembelajaran matematika diperlukan suatu metode mengajar yang bervariasi. Artinya dalam penggunaan metode mengajar tidak harus sama untuk semua pembahasan (Dhiu, 2019).

Berdasarkan observasi, yang dilakukan terhadap siswa dan guru matematika SMPK Swadaya Maukaro, metode pembelajaran yang digunakan cenderung masih menggunakan metode konvensional. Guru hanya memberi teori dan contoh soal serta pembahasan kemudian tugas. Keadaan seperti ini membuat siswa menjadi bosan dan tidak punya keinginan untuk belajar matematika, Peran guru terlihat dominan, karena yang berperan aktif yaitu guru. Pemahaman yang dimiliki siswa hanya sebatas apa yang disampaikan oleh pengajar, siswa tidak bisa mengembangkan materi tersebut lebih luas tetapi hanya bisa mengikuti langkah guru tanpa berpikir kreatif. Berdasarkan uraian diatas maka peneliti melakukan penelitian menggunakan strategi Guide Note Taking atau catatan terbimbing. Strategi Guide Note Taking atau catatan terbimbing merupakan salah satu strategi pembelajaran active learning yang dipilih untuk meningkatkan minat belajar siswa dalam pembelajaran matematika khusus pada siswa VIII SMPK Swadaya Maukaro. Oleh karena itu minat belajar siswa sangat penting untuk dikembangkan pada diri siswa agar memiliki kesadaran pada diri sendiri untuk belajar dan mencapai hasil yang diinginkan. 
Penerapan Metode Pembelajaran Guide Note Taking (GNT) Untuk Materi SPLDV

Pada Siswa Kelas VIII SMPK Swadaya Maukaro

Maria Anita Sero ${ }^{1,}$ Juwita Merdja ${ }^{2}$, Ariswan Usman Aje ${ }^{3}$

Jupika: Jurnal Pendidikan Matematika, Volume 3. Nomor 2. September 2020. Hal.101-110

Minat belajar siswa sangat berpengaruh terhadap hasil belajar siswa (Meke, dkk, 2020:175). Hal ini sejalan dengan penelitian oleh Fitrianingrum, (2017) kebiasaan dan minat dalam belajar sangat mempengaruhi hasil belajar siswa secara signifikan karena semakin tinggi minat belajar maka semakin tinggi pula hasil belajar yang diperolehnya. Menurut Sudjana (dalam Wondo, dkk. 2020) hasil belajar ialah kemampuan yang dimiliki oleh siswa setelah menerima pengalaman belajar. Hal ini sejalan dengan penelitian. Hal itu senada dengan pendapat (Hamalik, 2002) yang menyatakan bahwa"hasil belajar itu dapat terlihat dari terjadinya perubahan dari persepsi dan perilaku termasuk juga perbaikan perilaku". Misalnya pemuasan kebutuhan masyarakat dan pribadi secara utuh. Belajar merupakan proses yang kompleks dan terjadinya perubahan perilaku pada saat proses belajar diamati pada perubahan perilaku siswa setelah dilakukan penilaian. Guru harus dapat mengamati terjadinya perubahan tingkah laku tersebut.

Menurut Silberman, (2012) Strategi Guide Note Taking adalah strategi yang menggunakan pendekatan belajar aktif (active learning). Secara termologi Guide Note Taking atau catatan terbimbing merupakan strategi dimana seorang guru menyiapkan suatu bagan, skema (handoud) sebagai media yang dapat membantu siswa dalam membuat catatan apabila seorang guru sedang menyajikan pelajaran dengan metode ceramah. Adapun langkah-langkah strategi guide note taking menurut (Suprijono, 2012) yakni (1)Mempersiapkan sebuah hand-out yang menyimpulkan poin-poin penting dari pelajaran yang disampaikan dengan ceramah yang anda berikan. (2) Sebagai ganti tes yang lengkap, tinggalkan bagian tes itu kosong. (2) Bagian hand-out untuk siswa dan jelaskan bahwa anda telah membuat blangko-blangko untuk membantu mereka mendengarkan secara aktif pelajaran yang disampaikan dengan metode ceramah. Hal ini sejalan dengan penelitian nya Narjaikaew, dkk. (2009) penerapan model pembelajaran Guided Note Taking dapat meningkatkan aktivitas dan prestasi belajar. Senada dengan pendapat tersebut, bahwa penggunaan model pembelajaran Guided Note Taking dapat menunjukkan perbedaan yang signifikan antara kelas kontrol dan kelas eksperimen berdasarkan nilai rata-rata hasil belajarnya (Subroto, 2012). Berdasarkan hal tersebut, nampak jelas bahwa Guided Note Taking akan memberikan dampak yang positif terhadap belajar siswa. Adapun perbedaan dari penelitian sebelumnya, yakni penelitian ini memfokuskan pada pemberian catatan terbimbing (guided note taking) antara lain bahwa siswa akan menghasilkan catatan selama belajar yang lengkap dan akurat. Catatan terbimbing meningkatkan keaktifan siswa dalam menangkap isi dari materi pembelajaran. Siswa akan aktif menanggapi ceramah yang diberikan oleh guru dengan mendengarkan, melihat, memikirkan, dan menulis. Tujuan yang dicapai dalam penelitian ini adalah untuk mengetahui: (1) Untuk menghasikan perangkat pembelajaran Guide Note Taking (GNT) pada system persamaan linear dua variabel pada siswa kelas VIII SMPK Swadaya Maukaro tahun pelajaran 2018/2019. (2) Untuk mengetahui hasil belajar yang melalui metode Guide Note Taking (GNT) untuk materi sistem persamaan linear dua variabel siswa kelas VIII SMPK Swadaya Maukaro tahun pelajaran 2018/2019. 


\section{METODE}

Jenis penelitian yang dilakukan adalah penelitian eksperimen dengan pendekatan yang digunakan adalah peendekatan kuantitatif. Dalam penelitian ini yang menjadi populasi adalah semua siswa kelas VIII SMPK Swadaya Maukaro Tahun Pembelajaran 2018/2019. Sedangkan yang menjadi sampel adalah siswa kelas VIII(B) SMPK Swadaya Maukaro Tahun Pelajaran 2018/2019 yang berjumlah 20 orang sekaligus menjadi kelas eksperimen. Instrument yang digunakan adalah tes. Teknik pengumpulan data yang digunakan adalah teknik tes. Teknik analisis yang digunakan adalah ANAKOVA dengan menggunakan SPSS 16.00.

\section{HASIL DAN PEMBAHASAN}

Hasil validasi, validator mengatakan bahwa RPP, LKS, dan THB yang telah disusun sudah sesuai dengan yang diharapkan, dan validator merekomendasikan untuk dilakukan uji coba perangkat. pada kelas uji coba peneliti melakukan uji coba perangkat pembelajaran pada kelas uji coba, dimana kelas uji coba ini karakteristiknya sama dengan kelas eksperimen atau kelas penelitian sebenarnya. Pada kelas uji coba diberikan perlakuan yaitu melaksanakan dengan Strategi Guide Note Taking. Setelah selesai melaksanakan uji coba perangkat, peneliti menganalisis hasil pre-test dan post-test untuk mengetahui validitas, realibilitas dan sensitivitas butir, dengan hasilnya adalah sebagai berikut:

1. Validitas

Hasil perhitungan validitas setiap butir tes dengan menggunakan rumus korelasi produck moment disajikan pada tabel berikut:

Tabel 1. Validitaas Butir THB

\begin{tabular}{|l|l|l|l|}
\hline \multicolumn{1}{|c|}{ No. Soal } & \multicolumn{1}{c|}{$\mathbf{1}$} & \multicolumn{1}{c|}{$\mathbf{2}$} & \multicolumn{1}{c|}{$\mathbf{3}$} \\
\hline $\mathrm{r}_{\mathrm{xy}}$ & 0.65 & 0.74 & 0.90 \\
\hline Kriteria & Tinggi & Tinggi & Sangat Tinggi \\
\hline
\end{tabular}

Berdasarkan kriteria kelayakan butir tes, maka setiap butir tes dikategorikan valid dan layak digunakan dalam penelitian.

\section{Reliabilitas}

Berdasarkan hasil perhitungan reliabilitas tes diperoleh koefisien reliabilitas sebesar 0,47, kriteria "cukup" selengkapnya dapat dilihat pada lampiran. Jadi instrument penelitian ini memenuhi kriteria reliabel dan dapat digunakan untuk penelitian selanjutnya.

3. Sensitivitas

Hasil perhitungan sensitivitas setiap butir disajikan dalam tabel adalah sebagai berikut:

Tabel 2. Sensitivitas Butir Tes

\begin{tabular}{|l|l|l|l|}
\hline \multicolumn{1}{|c|}{ No. Soal } & \multicolumn{1}{c|}{$\mathbf{1}$} & \multicolumn{1}{c|}{$\mathbf{2}$} & \multicolumn{1}{c|}{$\mathbf{3}$} \\
\hline Sensitivitas & 0.72 & 0.74 & 0.66 \\
\hline Interpretasi & Peka & Peka & Peka \\
\hline
\end{tabular}


Hal ini berarti semua butir tes memenuhi kriteria sensitive sehingga layak digunakan dalam penelitian eksperimen.

Setelah selesai melaksanakan penelitian, selanjutnya peneliti memeriksa hasil pre-test dan post-test yang kemudian dianalisis dengan statistik Anakova. Tujuannya adalah untuk mengetahui seberapa besar efek dari perlakukan dalam hal ini adalah pemberian Strategi Guide Note Taking yang diberikan kepada siswa. Hasil analisisnya adalah sebagai berikut:

Tabel 3. Persiapan Analisis Data

\begin{tabular}{|c|c|c|c|c|c|c|}
\hline No & Pre (X) & Post & Perubahan $(\mathbf{Y})$ & Pre (X) & Post & $\begin{array}{c}\text { Perubahan } \\
(\mathbf{Y})\end{array}$ \\
\hline 1 & 25 & 85 & 60 & 25 & 92 & 67 \\
\hline 2 & 35 & 75 & 40 & 25 & 80 & 55 \\
\hline 3 & 20 & 80 & 60 & 20 & 80 & 60 \\
\hline 4 & 35 & 90 & 55 & 35 & 85 & 50 \\
\hline 5 & 30 & 90 & 60 & 30 & 92 & 62 \\
\hline 6 & 22 & 85 & 63 & 27 & 83 & 56 \\
\hline 7 & 25 & 80 & 55 & 30 & 100 & 70 \\
\hline 8 & 30 & 95 & 65 & 20 & 95 & 75 \\
\hline 9 & 22 & 84 & 62 & 25 & 85 & 60 \\
\hline 10 & 35 & 90 & 55 & 30 & 100 & 70 \\
\hline & $\mathbf{2 7 9}$ & & $\mathbf{5 7 5}$ & $\mathbf{2 6 7}$ & & $\mathbf{6 2 5}$ \\
\hline
\end{tabular}

Tabel 4. Hasil Reduksi Variabel X dan Variabel Y

\begin{tabular}{|c|c|c|c|c|c|c|c|c|}
\hline No & \multicolumn{2}{|c|}{$\mathbf{X}$} & \multicolumn{2}{|c|}{$\mathbf{Y}$} & \multirow{2}{*}{$\begin{array}{c}\text { Tot } \mathbf{X} \\
50\end{array}$} & \multirow{2}{*}{$\begin{array}{c}\text { Tot } \mathbf{Y} \\
127\end{array}$} & \multirow{2}{*}{$\begin{array}{c}\begin{array}{c}\text { Tot } \\
\text { (XY) }\end{array} \\
6350\end{array}$} & \multirow{2}{*}{$\frac{\mathbf{X i} * \mathbf{Y i}}{3175}$} \\
\hline 1 & 25 & 25 & 60 & 67 & & & & \\
\hline 2 & 35 & 25 & 40 & 55 & 60 & 95 & 5700 & 2775 \\
\hline 3 & 20 & 20 & 60 & 60 & 40 & 120 & 4800 & 2400 \\
\hline 4 & 35 & 35 & 55 & 50 & 70 & 105 & 7350 & 3675 \\
\hline 5 & 30 & 30 & 60 & 62 & 60 & 122 & 7320 & 3660 \\
\hline 6 & 22 & 27 & 63 & 56 & 49 & 119 & 5831 & 2898 \\
\hline 7 & 25 & 30 & 55 & 70 & 55 & 125 & 6875 & 3475 \\
\hline 8 & 30 & 20 & 65 & 75 & 50 & 140 & 7000 & 3450 \\
\hline 9 & 22 & 25 & 62 & 60 & 47 & 122 & 5734 & 2864 \\
\hline 10 & 35 & 30 & $55 \mathrm{~s}$ & 70 & 65 & 125 & 8125 & 4025 \\
\hline & 279 & 267 & 575 & 625 & 546 & 1200 & 65085 & 32397 \\
\hline & 27.9 & 26.7 & 57.5 & 62.5 & 298116 & 1440000 & & \\
\hline & 77841 & 71289 & 330625 & 390625 & 14905.8 & 72000 & 3254.25 & 3239.7 \\
\hline & 778.41 & 712.89 & 3306.25 & 3906.25 & 27.3 & 60 & & \\
\hline & \multicolumn{2}{|c|}{149130} & \multicolumn{2}{|c|}{721250} & & & & \\
\hline & \multicolumn{2}{|c|}{14913} & \multicolumn{2}{|c|}{72125} & & & & \\
\hline
\end{tabular}

Karena adanya korelasi antara variabel $\mathrm{X}$ dan variabel $\mathrm{Y}$, maka langkah pertama adalah memurnikan variabel $\mathrm{Y}$ dari variabel konkomitan (pengiring) $\mathrm{X}$, atau memperoleh Y yang disesuaikan atau dikorelasi.

Tabel 5. Korelasi Variabel X dan Variabel Y 


\begin{tabular}{|c|c|c|c|c|c|c|c|c|c|}
\hline \multirow{2}{*}{ No } & \multicolumn{2}{|c|}{$\mathbf{X}^{\wedge} \mathbf{2}$} & \multicolumn{2}{c|}{$\mathbf{Y}^{\wedge} \mathbf{2}$} & \multicolumn{2}{c|}{$\mathbf{X Y}$} & Tot & $\begin{array}{c}\text { Tot } \\
\left(\mathbf{X}^{\wedge} \mathbf{2}\right)\end{array}$ & $\begin{array}{c}\text { Tot } \\
\left(\mathbf{Y}^{\wedge} \mathbf{2}\right)\end{array}$ \\
\cline { 2 - 10 } & $(\mathbf{X Y})$ \\
\hline 1 & 625 & 625 & 3600 & 4489 & 1500 & 1675 & 1250 & 8089 & 3175 \\
\hline 2 & 1225 & 625 & 1600 & 3025 & 1400 & 1375 & 1850 & 4625 & 2850 \\
\hline 3 & 400 & 400 & 3600 & 3600 & 1200 & 1200 & 800 & 7200 & 2400 \\
\hline 4 & 1225 & 1225 & 3025 & 2500 & 1925 & 1750 & 2450 & 5525 & 3675 \\
\hline 5 & 900 & 900 & 3600 & 3844 & 1800 & 1860 & 1800 & 7444 & 3660 \\
\hline 6 & 484 & 729 & 3969 & 3136 & 1386 & 1512 & 1213 & 7105 & 2915.5 \\
\hline 7 & 625 & 900 & 3025 & 4900 & 1375 & 2100 & 1525 & 7925 & 3437.5 \\
\hline 8 & 900 & 400 & 4225 & 5625 & 1950 & 1500 & 1300 & 9850 & 3500 \\
\hline 9 & 484 & 625 & 3844 & 3600 & 1364 & 1500 & 1109 & 7444 & 2867 \\
\hline 10 & 1225 & 900 & 3025 & 4900 & 1925 & 2100 & 2125 & 7925 & 4062.5 \\
\hline JML & $\mathbf{8 0 9 3}$ & $\mathbf{7 3 2 9}$ & $\mathbf{3 3 5 1 3}$ & $\mathbf{3 9 6 1 9}$ & $\mathbf{1 5 8 2 5}$ & $\mathbf{1 6 5 7 2}$ & $\mathbf{1 5 4 2 2}$ & $\mathbf{7 3 1 3 2}$ & $\mathbf{3 2 5 4 2 . 5}$ \\
\hline
\end{tabular}

Koreksi atau penyesuaian karena adanya regresi $\mathrm{Y}$ atas $\mathrm{X}$ terhadap jumlah kuadrat variabel $\mathrm{Y}$ dapat dihitung dengan:

\section{Jumlah Total}

$J_{E}^{1}=J K(Y$ dikoreksi $)=T_{Y Y}-\frac{\left(T_{X Y}\right)^{2}}{T_{X X}}=876.733$

\section{Dalam Perlakuan Kelompok}

$J_{E}^{1}=J K(Y$ dikoreksi $)=E_{Y Y}-\frac{\left(E_{X Y}\right)^{2}}{E_{X X}}=-1669225.11$

\section{Antar Kelompok}

$J_{E}^{1}=J K(Y$ dikoreksi $)=108$

Dari hasil perhitungan ini selanjutnya disajikan dalam tabel ANAKOVA berikut:

Tabel 6. Daftar Anakova Model Pembelajaran

\begin{tabular}{|l|l|l|l|l|l|l|l|l|}
\hline \multirow{2}{*}{$\begin{array}{l}\text { Sumber } \\
\text { Variasi }\end{array}$} & \multirow{2}{*}{ Dk } & \multicolumn{3}{|c|}{ JK dan Produk Silang } & \multicolumn{3}{|c|}{ Dikoreksi } & \multirow{2}{*}{ F } \\
\cline { 3 - 8 } & 1 & Y & \multicolumn{1}{|c|}{ XY } & X & Y & Dk & KT & \\
\hline $\begin{array}{l}\text { Antar } \\
\text { Kelompok }\end{array}$ & 125 & -29520.3 & 7.2 & & & & \\
\hline $\begin{array}{l}\text { Dalam } \\
\text { Kelompok }\end{array}$ & 18 & 1007 & 29157.3 & 509 & -1669225.11 & 17 & & \\
\hline Jumlah & 19 & 1132 & -362.999766 & 516.2 & 876.733 & 18 & & \\
\hline $\begin{array}{l}\text { Antar } \\
\text { Kelompok }\end{array}$ & & & & & 108 & 1 & 108 & 5.241 \\
\hline
\end{tabular}

Dari tabel ANAKOVA diatas, untuk menguji efek pembelajaran dalam kelompok eksperimen terhadap respon $\mathrm{Y}$ setelah dimurnikan dari variabel konkomitan $\mathrm{X}$, diperoleh statistik $\mathrm{F}=$ 5.241 dan $\mathrm{f}$ tabel $=4,45$ dengan $\mathrm{dk}$ pembilang $=1 \mathrm{dan} \mathrm{dk}$ penyebut 17 , memberikan nilai yang signifikan.

\section{Regresi Dalam Perlakuan}

Dengan memperhatikan model ANAKOVA yaitu: 
$Y_{i j}=\mu+\beta\left(X_{i j}-\bar{X}\right)+\tau_{i}+\varepsilon_{i j} ; i=1,2,3, \ldots, k ; j=1,2,3, \ldots n_{k}$

Nilai parameter yang diduga dengan metode kuadrat terkecil:

1. Koefisien regresi $\beta$ ditaksir oleh $b=\frac{E_{X Y}}{E_{X X}}=57.28$

2. $\mu$ ditaksir oleh $: \frac{J_{Y}}{N}$

$$
\mu=\frac{\sum Y}{n}=60
$$

3. $\tau_{i}$ ditaksir oleh: $\frac{J_{Y i}}{n_{i}}-b\left(\frac{J_{X i}}{n_{i}}-\frac{J_{X}}{N}\right)$

Perlakuan $\mathrm{A}\left(\tau_{A}\right)=87.30$

Perlakuan $\mathrm{B}\left(\tau_{B}\right)=27.30$

\section{Tabel 7. Nilai Rata-Rata Koreksi Kelompok}

\begin{tabular}{|c|c|c|}
\hline Perlakuan Kelompok & Rt Dikoreksi & Rt Tdk Dikoreksi \\
\hline A & 87.30 & 87.76 \\
\hline B & 27.30 & 27.08 \\
\hline
\end{tabular}

Dari tabel tersebut di atas tampak bahwa perbedaan rata-rata yang dikoreksi atau disesuaikan harga-harga lebih kecil perbedaannya dari yang satu dengan yang lainnya jika dibandingkan dengan rata-rata yang tidak dikoreksi.

Model yang diperoleh dalam eksperimen adalah:

$\mathrm{Y}_{\mathrm{A}}=60.00+57.28 \mathrm{X}+87.30$

$\mathrm{Y}_{\mathrm{B}}=60.00+57.28 \mathrm{X}+27.30$

\section{Pemeriksaan Residual}

Setelah diperoleh nilai estimasi parameter, maka langkah selanjutnya adalah melakukan uji normalitas residual. Pengujian kenormalan residual menggunakan uji Kolmogorov-Smirnov dengan hipotesis sebagai berikut:

$\mathrm{H}_{0}$ : Residual berdistribusi normal

$\mathrm{H}_{1}$ : Residual tidak berdistribusi normal

\section{Regression Analysis: $\mathbf{y}$ versus $x$}

The regression equation is

$\mathrm{Y}=79.198-0.703$

Analysis of Variance

$\begin{array}{llllll}\text { Source } & \text { DF } & \text { SS } & \text { MS } & \text { F } & \text { P } \\ \text { Regression } & 1 & 0.933 & 0.933 & 0.000 & 0.347 \\ \text { Residual Error } & 18 & 876.733 & 48.707 & & \\ \text { Total } & 19 & 877.666 & & & \end{array}$

Durbin-Watson statistic $=1.689$

Uji identik dengan hipotesis sebagai berikut: 
$\mathrm{H}_{0}: \sigma_{1}^{2}=\sigma_{2}^{2}=\cdots=\sigma_{n}^{2}=\sigma^{2}$

$\mathrm{H}_{1}$ : Minimal ada satu $\sigma_{1}^{2} \neq \sigma^{2} ; i=1,2, \ldots, n$

Pada tingkat signifikansi 5\%. Nilai $\mathrm{f}$-hitung $=0,000<\mathrm{f}$-tabel $=4.45$ atau dapat dilihat nilai P-value $=$ $0.347>\alpha=0.05$ yang menyimpulkan bahwa dalam kasus ini varians telah homogen.

a. Uji independen

Uji independen dapat dilakukan dengan hopotesis sebagai berikut:

$\mathrm{H}_{0}: \rho_{i}=0$ atau residual tidak berkorelasi

$\mathrm{H}_{1}: \rho_{i} \neq 0$ atau residual berkorelasi

$\alpha=0.05$

Durbin-Watson statistic $=1.689$

pada tingkat signifikansi $5 \%$. Nilai p-value $=0.347>\alpha=0.05$ yang menyimpulkan bahwa dalam kasus ini residual tidak berkorelasi atau gagal tolak $\mathrm{H}_{0}$. Dengan kriteria Durbin-Watson tes $\mathrm{d}=1.689$ tidak ada korelasi antar residual.

b. Uji normalitas

Pengujian normalitas dapat dilakukan dengan hipotesis sebagai berikut:

$\mathrm{H}_{0}$ : Residual berdistribusi normal

$\mathrm{H}_{1}$ : Residual tidak berdistribusi normal

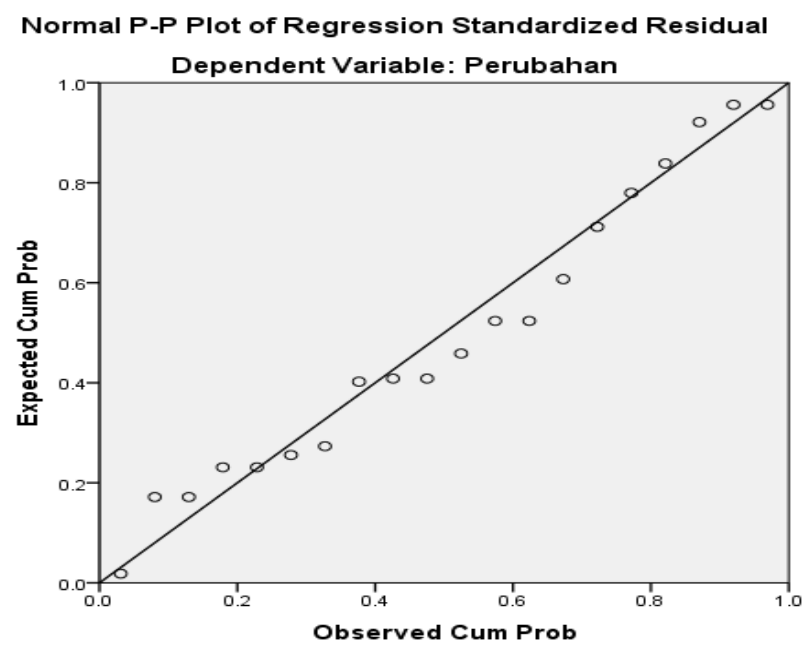

\section{Gambar 1. Plot Normaalitas Residual}

Plot normalitas residual menunjukkan tidak ada penyimpangan terhadap distribusi normal. Hal ini diperkuat dengan menggunakan uji Kolmogorov-Smirnov yang memberikan p-value $=0.347>0.05$ sehingga gagal tolak $\mathrm{H}_{0}$ atau residual berdistribusi normal.

Dalam prosesnya, pembelajaran matematika menggunakan metode GNT layak untuk diaplikasikan dalam pembelajaran matematika. Metode GNT teridentifikasi mampu meningkatkan hasil belajar matematika siswa. Penelitian ini sejalan hasil penelitian Riyadi (2016:76) yang menyimpulkan bahwa metode pembelajaran kooperatif tipe GNT mampu memberikan motivasi belajar matematika yang baik. 
Penerapan Metode Pembelajaran Guide Note Taking (GNT) Untuk Materi SPLDV

Pada Siswa Kelas VIII SMPK Swadaya Maukaro

Maria Anita Sero ${ }^{1, J u w i t a}$ Merdja ${ }^{2}$, Ariswan Usman $\mathrm{Aje}^{3}$

Jupika: Jurnal Pendidikan Matematika, Volume 3. Nomor 2. September 2020. Hal.101-110

\section{KESIMPULAN}

Berdasarkan dari hasil penelitian dan pembahasan pada bab sebelumnya menyimpulkan bahwa dari hasil penyusunan perangkat pembelajaran Guide Note Taking untuk materi sistem persamaan linear dua variabel menghasilkan perangkat pembelajaran yang baik, karena memenuhi syarat berdasarkan validitas, reliabilitas dan sensitivitas. Dari hasil analisis data kovarian diperoleh f-hitung $=5.241>\mathrm{f}$-tabel $=4.45$ atau dapat dilihat nilai $\mathrm{P}$-value $=0.347>\alpha=0.05$ dengan dk pembilang 1 dan dk penyebut 19, memberikan nilai yang signifikan, maka hal ini menunjukkan bahwa pembelajaran Guide Note Taking dinilai dapat meningkatkan hasil belajar untuk materi sistem persamaan linear dua variabel pada siswa kelas VIII SMPK Swadaya Maukaro Tahun Pelajaran 2018-2019.

\section{DAFTAR PUSTAKA}

Dhiu, A. (2019). Model Pembelajaran Numbered Head Together (NHT) Untuk Materi Pokok Relasi dan Fungsi Pada Siswa Kelas VIIII SMPN 1 Bajawa. Jurnal: Scientifical Colloquia: Jurnal Pendidikan Matematika Universitas Flores, 2 (September), 9-18.

Fitrianingrum, L. (2017). Pengaruh Minat Belajar Terhadap Hasil Belajar Mata Pelajaran Ilmu Pengetahuan Alam Siswa Kelas V di MI Muhammadiyah Karanglo Kecamatan Cilongok Kabupaten Banyumas. Skripsi thesis, IAIN.

Hamalik, O. (2002). Pendidikan Guru Konsep dan Strategi. Bandung: Mandar Maju.

Lebi, D. E. U. (2020). Pembelajaran Kooperatif Tipe STAD untuk Materi Himpunan Pada Siswa Kelas VII SMP Swasta Muhammadiyah Ende tahun Pelajaran 2014/2015. Jurnal Scientifical Colloquia: Jurnal Pendidikan Matematika Universitas Flores, 3, 33-40.

Meke, K.D.P, et al dkk. (2020). Pembelajaran problem based learning dengan penggunaan bahan manipulatif di tinjau dari minat belajar matematika. Jurnal Penelitian dan Pembelajaran Matematika 13(2), 164-177

Narjaikaew , P., Emarat, N, \& Cowie , B.(2009) . The Effect of Guided Note Taking Guring Lectures on Thai University Students' Understanding Electromagnetism. https://doi.org/10.1080/02635140802658917

Pleimaget, Y. (2019). Pembelajaran Kooperatif Tipe Numbered Head Together Materi Bilangan Bulat Pada Siswa Kelas SMPN 1 Wulanggitan Tahun Pelajaran 2014/2015. Scientifical Colloquia: Jurnal Pendidikan Matematika Universitas Flores, 2(1), 7-13.

Rachmayani, D. (2014). Penerapan Pembelajaran Reciprocal Teaching Untuk Meningkatkan Kemampuan Komunikasi Matematis Dan Kemandirian Belajar Matematika Siswa. Jurnal Pendidikan Unsika, 2(1), 13-23. https://journal.unsika.ac.id/index.php/judika/article/view/118

Riyadi, J. S. (2016). Pembelajaran matematika guided note taking dan PBL ditinjau dari motivasi belajar untuk pencapaian kemampuan pemecahan masalah. Pasundan Journal of Mathematics Education.6(2),68-80

Silberman, M. L. (2012). Active Learning 101 cara belajar Siswa Aktif. Bandung: Nuansa.

Subroto, T. (2012). Model Pembelajaran Guided Note Taking Berbantuan Media ChemoEdutainment pada Materi Pokok Koloid. Jurnal Pendidikan IPA Indonesia, 1(1). 
Penerapan Metode Pembelajaran Guide Note Taking (GNT) Untuk Materi SPLDV

Pada Siswa Kelas VIII SMPK Swadaya Maukaro

Maria Anita Sero 1 ,Juwita Merdja ${ }^{2}$, Ariswan Usman $\mathrm{Aje}^{3}$

Jupika: Jurnal Pendidikan Matematika, Volume 3. Nomor 2. September 2020. Hal.101-110

Suherman, E. (2001). Pembelajaran Matematika Kontempoler. Bandung: JICA.

Suprijono, A. (2012). Cooperative Learning: Teori dan Aplikasi Paikem. Yogyakarta: Pustaka Belajar.

Syaiful, S. (2003). Konsep dan Makna Pembelajaran. Bandung: Alfabeta.

Wondo, M. T. S., Mei, M. F., \& Seto, S. B. (2020). Penggunaan Media Geogebra dalam Pembelajaran Geometri Ruang untuk Meningkatkan Minat dan Hasil Belajar Mahasiswa. Jurnal Pendidikan Matematika FKIP Universitas Halu Oleo, 11(1), 134-142. 